\title{
PROPOSED MACRO-MODEL FOR THE ANALYSIS OF INFILLED FRAME STRUCTURES
}

\author{
Francisco J. Crisafulli ${ }^{1}$ and Athol J. Carr ${ }^{2}$
}

\begin{abstract}
Reinforced concrete frames infilled with masonry panels constitute an important part of the high-risk structures in different regions of high seismicity. In some developing countries, they are still used as main structural system for low to medium rise buildings. Consequently, reliable methods to analyse infilled frames are required in order to reduce the loss of life and property associated with a possible structural failure.

The equivalent strut model, proposed in the 1960s, is a simple procedure to represent the effect of the masonry panel. Several improvements of the original model have been proposed, as a result of a better understanding of the behaviour of these structures and the development of computer software. This paper presents a new macro-model for the evaluation of the global response of the structure, which is based on a multi-strut formulation,. The model, implemented as 4-node panel element, accounts separately for the compressive and shear behaviour of masonry using a double truss mechanism and a shear spring in each direction. The principal premises in the development of the model are the rational consideration of the particular characteristics of masonry and the adequate representation of the hysteretic response. Furthermore, the model is able to represent different modes of failure in shear observed for masonry infills. The comparison of analytical results with experimental data showed that the proposed model, with a proper calibration, is able to represent adequately the in-plane response of infilled frames.
\end{abstract}

\section{INTRODUCTION}

Infilled frames are complex structures which exhibit a highly nonlinear inelastic behaviour. The most important factors contributing to this behaviour arise from material nonlinearity, namely, (i) cracking and crushing of the masonry panel, (ii) cracking of the concrete, yielding of the reinforcing bars and local bond slip in the surrounding frame, and (iii) degradation of the bond-friction mechanism and variation of the contact length along the panel-frame interfaces. Geometric nonlinear effects can also occur in infilled frames, especially when the structure is able to resist large horizontal displacements. However, these effects do not present any particularity and can be considered in the analysis using the same methodologies applied to reinforced concrete or steel structures. The nonlinear effects mentioned above introduce analytical complexities which required sophisticated computational techniques to be properly considered in the modelling. Furthermore, some mechanical properties are difficult to define accurately, especially those of masonry and of the panel-frame interfaces. These facts complicate the analysis of infilled frames and represent one of the principal reasons to explain why infill panels has been considered as "non-structural elements", despite their strong influence on the global response.
Different modelling techniques have been used for the analysis of infilled frames, which can be divided into two main groups: (i) local or micro-models and (ii) simplified or macro-models, Crisafulli, et al., 2000. The first group involves the models in which the structure is divided into numerous elements (usually of different types) to take account of the local effects in detail, whereas the second group includes simplified models based on a physical understanding of the behaviour of the infill panel. In the later case, a few elements are used to represent the effect of the masonry infill as a whole. Both types of models present advantages and disadvantages, and the selection of the more adequate option should consider the characteristics of each case and the objectives of the analysis. The typical example of the macro-model for infilled frames is the diagonal strut model, see Fig. 1 (a), developed several decades ago based on the analytical work conducted by Polyakov (as reported by Mallick and Severn, 1967). Later, Holmes, 1961, proposed that the equivalent diagonal strut should have a width equal to one third of the length of the panel and Stafford Smith, 1962, improved the approach based on experimental data. This task was continued by many other researchers, who refined the model, mainly by considering several struts to represent the panel (a more complete description can be found elsewhere, Crisafulli, 2000).

\footnotetext{
${ }^{1}$ Facultad de Ingeniería, Universidad Nacional de Cuyo. Mendoza, Argentina (Member). E-mail:jcrisa@uncu.edu.ar

${ }^{2}$ Department of Civil Engineering, University of Canterbury. Christchurch, New Zealand (Fellow).
} 
In order to analyse large structures or complete buildings, it seems that a simple, but physically reasonable model constitutes the best alternative. Consequently, this paper presents the development and implementation of a macro-model for the representation of the masonry panel in infilled frames. This model considers a multi-strut formulation, which can be useful when the objective of the analysis focuses on the global response of the structure.

\section{PRELIMINARY STUDY}

A preliminary study was conducted to investigate the limitations of the single strut model and the influence of different multi-strut models on the structural response of the infilled frame. The study focussed on the lateral stiffness of the structure and on the actions induced in the surrounding frame. Figure 1 illustrates the three strut models considered in the study, which are referred as Model A, B and C, respectively. The total area of the equivalent masonry strut, $A_{m s}$, was the same in all the cases. It was assumed in Model $C$ that the sectional area of the central strut was the double of that corresponding to the off-diagonal struts. The separation between the struts in Models B and C was adopted as a fraction of the contact length, z, defined by Stafford Smith, 1966,

It must be noted that the models shown in Figure 1 are valid for static analysis because the struts are located in order to represent the diagonal compressive field that develops in the panel. When the structure is subjected to cyclic or dynamic loading, the diagonal struts should change according the direction of the loading.

The use of only one diagonal strut resisting compressive and tensile forces cannot describe properly the internal forces induced in the members of the frame. In this case, at least two struts following the diagonal directions of the panel must be considered to represent approximately the effect of the masonry infill. It is usually assumed that the diagonal struts are active only when subjected to compressive forces. However, compression-only elements are not available in common elastic computer programs. In this case, it is recommend the use of tension-compression truss members in both directions with half of the equivalent strut area in each diagonal direction. The use of this simplified model results in significant changes in the internal forces in the surrounding frame, especially the axial forces in the columns (tensile forces decrease, whereas compressive forces increase). The assumption of a compression-only strut is acceptable on the basis that the bond strength at the panel-frame interfaces and the tensile strength of the masonry are very low. Tensile forces, therefore, can be transferred through the interfaces only for small levels of seismic excitation. This consideration may not be valid when either shear connectors are used at the interfaces or the masonry panel is reinforced with horizontal or vertical bars. Refined models, however, can consider the tensile behaviour, which usually does not affect significantly the results. (a) Model A

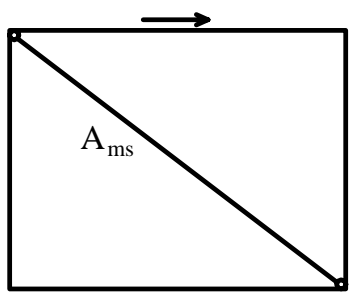

(b) Model B

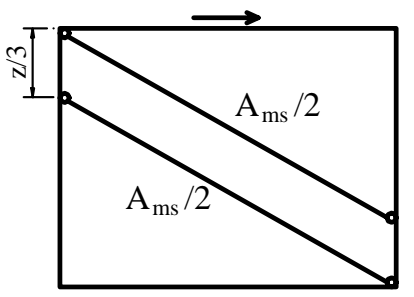

(c) Model C

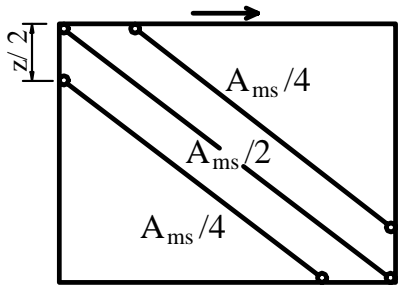

Figure 1. Strut models considered in the preliminary study.

Numerical results obtained from the strut models A, B and C were compared with those corresponding to a refined finite element model (FEM) implemented with the program ABAQUS. The general characteristics of this model are described by Crisafulli, 1997. The lateral stiffness of the structure was similar in all the cases considered, with smaller values for models B and C. It must be noted that, for the multistrut models, the stiffness may significantly change depending on the separation between struts. Figure 2 compares the bending moment diagrams obtained from one typical example according to the different models used in this study. Model A underestimates the bending moment because the lateral forces are primarily resisted by a truss mechanism. On the other hand, Model B leads to larger values than those corresponding to the finite element model. A better approximation is obtained from Model C, although some differences arise at the ends of both columns. Similar conclusions can be drawn regarding the shear forces. The maximum axial forces in the frame members are approximately equal in all the models, even though the variation of the axial forces along the columns shows some discrepancy at the top end of the tension column and at the bottom end of the compression column.

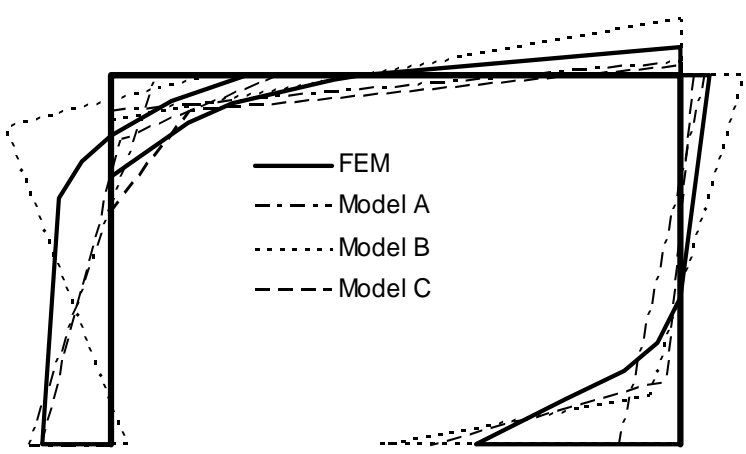

Figure 2. Bending moment diagrams obtained from different models .

It can be concluded that the single strut model, despite its simplicity, can provide an adequate estimation of the stiffness of the infilled frame and the axial forces induced in the frame 
members by lateral forces. However, a more refined model, Model C, is required in order to obtain realistic values of the bending moments and shear forces in the frame.

\section{FAILURE MODES OF THE MASONRY PANEL}

According to the literature, the most common types of failure are, Crisafulli, 1997:

- shear failure due to debonding of the mortar-brick interfaces (shear-friction failure), which can occur following a stepped cracking pattern or by horizontal sliding along a mortar joint,

- diagonal tension failure of the masonry units, as a result of a combination of compressive and shear stresses in the masonry, and

- crushing of the masonry at the corners due to high compressive stresses.

Macro-models, due to their simplicity, cannot represent precisely all the different types of failure observed for masonry panels. For this reason, a preliminary study should be conducted before modelling the structure in order to estimate the expected mode of failure of the masonry panel. This can be achieved by applying the failure theory proposed by Mann and Müller (1982) or by Crisafulli et al. (1995) and (2002). After this preliminary study, the failure of masonry can be adequately considered in the model using a proper combination of strut and shear springs.

The failure due to crushing of the masonry at the corners is uncommon for infilled reinforced concrete frames, although it has been observed in infilled steel frames. In this case, the surrounding frame is more flexible and the contact length between the panel and the frame is smaller. This situation can be also represented with the triple strut model illustrated in Fig. 3 , in which the central strut is divided into two elements with different areas, in order to consider approximately the increase of axial stresses occurring in the corners of the panels. It is worth noting that this idea is presented here in a general sense. The practical application of this model requires further research in order to investigate the values of the area and length of the reduced element of the central strut.

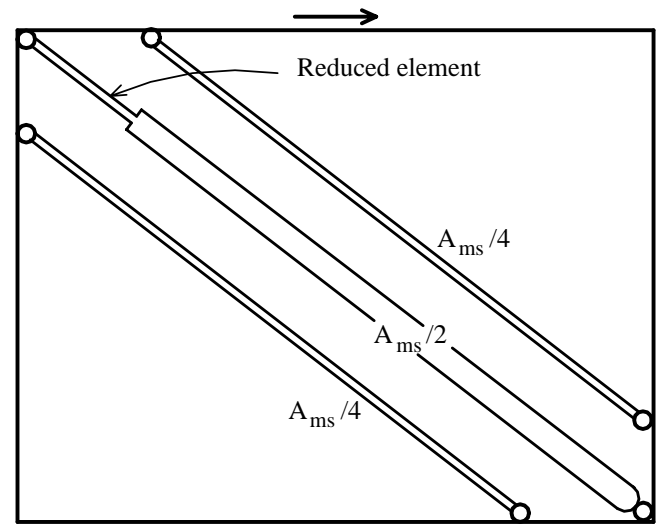

Figure 3. Multi-strut model proposed to represent the crushing of the masonry at the corners of the panel.

\section{PROPOSED MACRO-MODEL}

\subsection{General description of the model}

A new macro-model is proposed in this paper in order to represent, in a rational but simple way, the effect of masonry infill panels. The model is implemented as a 4-node panel element which is connected to the frame at the beam-column joints. Internally, the panel element accounts separately for the compressive and shear behaviour of the masonry panel using two parallel struts and a shear spring in each direction, see Fig. 4. This configuration allows an adequate consideration of the lateral stiffness of the panel and of the strength of masonry panel, particularly when a shear failure along mortar joints or diagonal tension failure is expected. Furthermore, the model is easy to apply in the analysis of large infilled frame structures. The main limitation of the model results from its simplicity, since the panel is connected to the beam-column joints of the frame it is not able to predict properly the bending moment and shear forces in the surrounding frame.

It is assumed in the model that the stiffness of the shear spring, $\mathrm{k}_{\mathrm{s}}$, is equal to a fraction, $\gamma_{\mathrm{s}}$, of the total stiffness of the masonry strut

$$
k_{s}=\gamma_{s} \frac{A_{m s} E_{m}}{d_{m}} \cos ^{2} \theta
$$

where $A_{m s}$ is the total area of the equivalent strut (defined by several researchers based on experimental and analytical data, see Crisafulli, 1997), $E_{m}$ is the elastic modulus of masonry and $d_{m}$ is the diagonal length of the masonry panel. The term $\cos ^{2} \theta$ is introduced in Eq. (1) to express the stiffness in the horizontal direction, being $\theta$ the inclination of the diagonal of the infill panel. The factor $\gamma_{\mathrm{s}}$ usually varies from 0.50 to 0.75 , according to the results obtained by the authors when calibrating the model.

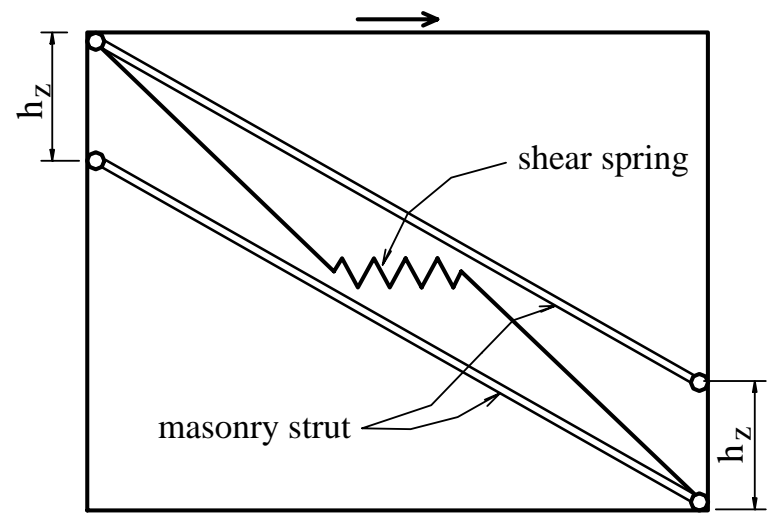

Figure 4. Proposed multi-strut model (only the struts and shear spring active in one direction are represented).

The hysteretic response of the shear spring is modelled following an elasto-plastic rule with variable shear strength (Crisafulli, 1997). The shear strength of the spring is controlled by a shear-friction mechanisms which can be adequately represented by the Mohr-Coulomb criterion. Therefore, the strength is evaluated considering two different stages, namely, (i) elastic response before the bond-shear strength is reached, 
and (ii) sliding, in which the strength depends on the compressive force of the struts. In the latter case, the shear strength is limited in order to avoid large values due to high axial forces in the struts.

The evaluation of the stiffness of the shear spring considered in the model, based on Eq. (1), does not reflect the actual shear behaviour of the masonry panel, but represents a practical approach which leads to adequate values of the lateral stiffness of the infilled frame. In this way, it is possible to use the existing empirical expressions proposed for the calculation of the equivalent width of the masonry strut. Additional experimental and analytical research is required in order to develop a more rational procedure which will be able to take into account the shear response of the infill panel not only in terms of strength but also in terms of stiffness.

The axial stiffness of each strut, $\mathrm{k}_{\mathrm{ai}}$, accounts for the remaining fraction $\left(1-\gamma_{s}\right)$ of the total stiffness which is assigned to two struts with equal area, see Fig. 1 (b):

$$
k_{a i}=\frac{\left(1-\gamma_{s}\right) A_{m s} E_{t}}{2 d_{m}}
$$

where $E_{t}$ is tangent modulus of the masonry defined according to an adequate hysteretic model for masonry. This is required in order to conduct nonlinear dynamic analyses of infilled frames subjected to earthquakes. In the proposed model, the response of the axial struts is represented according to a hysteretic stressstrain relationship developed by Crisafulli, 1997. The axial force and the axial displacement in the strut are related to the stress and strain of the masonry according to basic relationships of the structural analysis.

The area of the equivalent strut, $A_{m s}$, can decrease as the lateral displacement of the structure, and consequently the axial displacement of the strut, increases. This is due to the reduction of the contact length between the panel and the frame, and due to the cracking of the masonry infill. It is assumed in the proposed model that the area of the equivalent varies as a function of the axial displacement $\Delta_{\mathrm{a}}$, following the criterion illustrated in Fig. 5. The variation of the strut area $A_{m s}$ is introduced in the model to gain generality, even though there is insufficient information to estimate the practical values of this variation. According to experimental results reported by Decanini and Fantin (1986) the equivalent width of the strut decreases by about $20 \%$ to $50 \%$ due to cracking of the masonry panel. However, these values were derived under the assumption that the modulus $\mathrm{E}_{\mathrm{t}}$ remains constant, whereas the proposed model considers a variable modulus, which decreases as the axial compressive strain increases. The main advantage of this approach is that the user can control the variation of the stiffness and the axial strength of the masonry strut.

The response in the initial stage is primarily controlled by the shear spring and the bending moments and shear forces in the frame are similar to those obtained from the triple-strut model (Model C, Fig. 1). After the shear strength is reached and sliding starts, the mechanisms changes resulting in a significant increase of the actions induced in the frame.

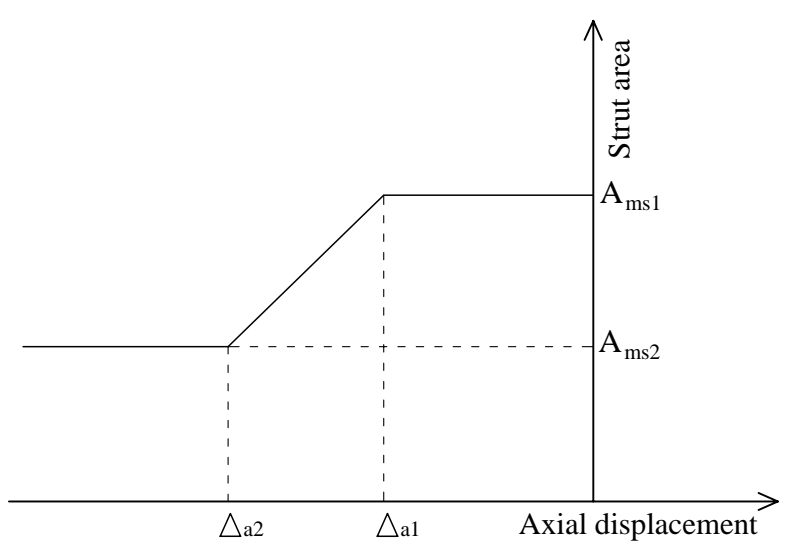

Figure 5. Variation of the strut area considered in the model.

\subsection{Formulation of the model}

The practical implementation of the proposed model requires the use of several spring elements and beam or beam-column elements to represent the masonry panel and the surrounding frame. In order to simplify the application of the proposed model, from the user point of view, a 4-node panel element has been formulated and implemented in the structural program RUAUMOKO (Carr, 2002). In this way, the user only needs to define the characteristics of the masonry infill as a whole element, whereas the program evaluates internally the properties of the struts and the shear spring. Fig. 6 illustrates the main characteristics of the proposed panel element.

The vertical separation of both struts, $h_{z}$, varies between $\mathrm{z} / 3$ and $\mathrm{z} / 2$, being $\mathrm{z}$ the contact length between the panel and the frame (Stafford Smith, 1966):

$$
z=\frac{\pi}{2 \lambda_{h}} h
$$

where $h$ is the storey height,

$$
\lambda_{h}=h \sqrt[4]{\frac{E_{m} t \sin \theta}{4 E_{c} I_{c} h_{m}}}
$$

$t$ is the masonry thickness, $E_{c}$ is the elastic modulus of the concrete, $I_{c}$ is moment of inertia of the columns and $h_{m}$ is the height of the masonry panel.

Three different sets of nodes are considered for the development of the panel element, namely, external nodes, internal nodes and dummy nodes. The external nodes are those connected to the principal structure, whereas the internal nodes are defined by a horizontal and a vertical offset, $\mathrm{x}_{\mathrm{oi}}$ and $\mathrm{y}_{\mathrm{oi}}$ respectively, measured from the external node $i$. This is intended to represent the reduction of the dimensions of the panel due to the depth of the frame members. 

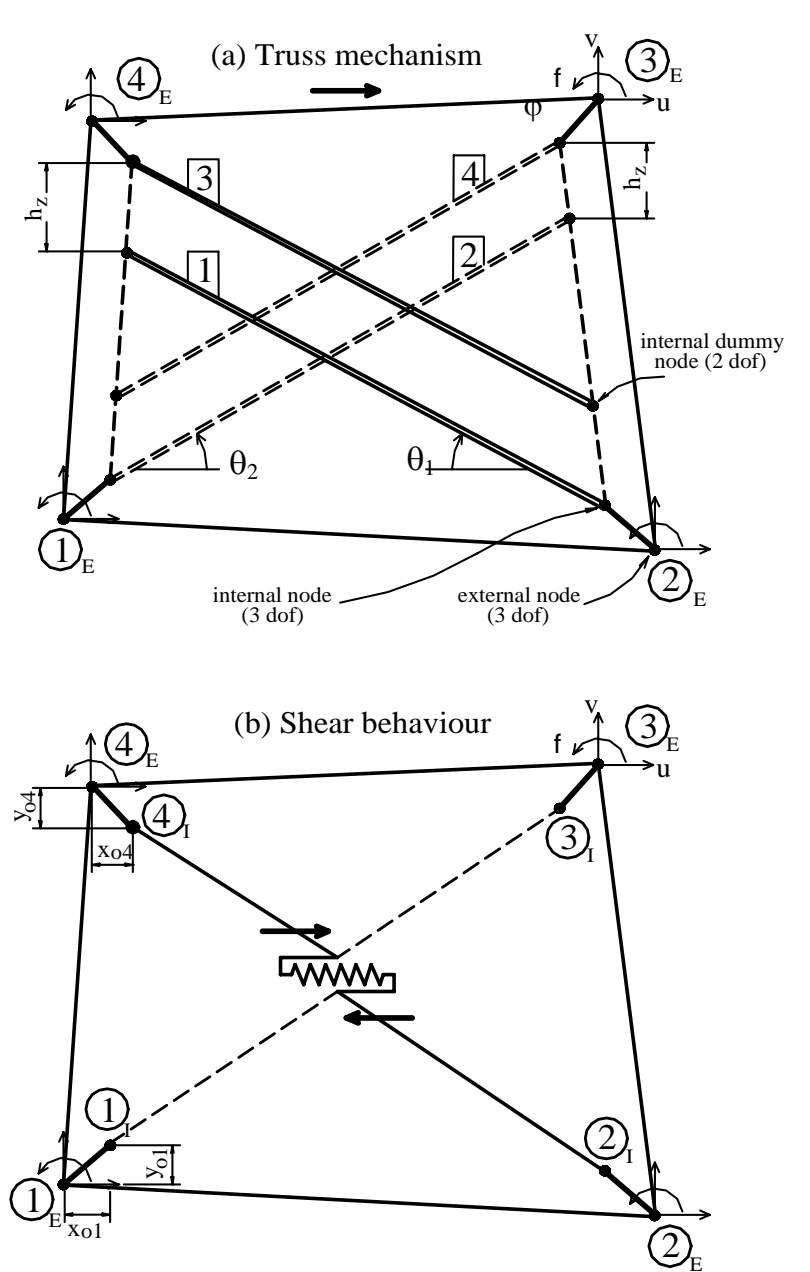

Figure 6. Proposed 4-node panel element.

Three degrees of freedom, the translations $u$ and $v$ and the rotation $\theta$, are considered in each of the external and internal nodes. Four dummy nodes, with 2 translational degrees of freedom per node, are required to define the end of the strut members which is not connected to the corners of the panel. The formulation of the stiffness matrix and the nodal forces of the panel element is conducted considering the equilibrium and compatibility equations between the forces and displacement of the different coordinates systems. These relationships, derived from the principle of Virtual Displacement (Livesly,1975), indicate that if a transformation matrix [Q] relates the displacements $\{\mathrm{u}\}_{\mathrm{A}}$ and $\{\mathrm{u}\}_{\mathrm{B}}$ expressed in two different systems of rectangular coordinates, the transpose of this matrix, $[\mathrm{Q}]^{\mathrm{T}}$, also transforms the nodal forces $\{\mathrm{F}\}_{\mathrm{B}}$ to $\{\mathrm{F}\}_{\mathrm{A}}$. It can be shown that the stiffness matrix in the coordinates system " $\mathrm{B}$ " is equal to the double product of the matrix [Q] applied to the stiffness matrix in the coordinates system " $\mathrm{A}$ ":

$$
\begin{aligned}
& \{u\}_{A}=[Q]\{u\}_{B}, \quad\{F\}_{B}=[Q]^{\mathrm{T}}\{F\}_{A} \\
& {[K]_{B}=[Q]^{\mathrm{T}}[K]_{\mathrm{A}}[Q]}
\end{aligned}
$$

These relationships are successively applied to transform the structural parameters of each strut and spring of the model to the global system of coordinates, associated with the external nodes of the panel element.

\subsection{Axial behaviour of the struts}

Eq. (2) gives the axial stiffness of each strut in local coordinates (referred to the axial displacement). Consequently, a series of transformations are required to obtain the stiffness matrix in global coordinates and related to the displacements of the external nodes of the panel element. This process is developed according to the structural concepts presented in Section 4.2, and comprises three transformations, which are described in the following paragraphs. Each transformation will be referred using the sub-index A, B and C.

The first transformation required in the analysis relates the axial displacement of the strut, $\Delta_{\mathrm{a}}$, to the horizontal and vertical displacements, $\mathrm{u}$ and $\mathrm{v}$, at the ends $\mathrm{j}$ and $\mathrm{k}$ of the strut:

$$
\Delta_{a}=[Q]_{A}\left\{\begin{array}{l}
u_{j} \\
v_{j} \\
u_{k} \\
v_{k}
\end{array}\right\}
$$

where the matrix $[\mathrm{Q}]_{\mathrm{A}}$ is defined as a function of the inclination of the strut referred to the global system, $\theta_{\mathrm{i}}$, see Fig. 6 (a):

$$
[Q]_{A}=\left[\begin{array}{llll}
-\cos \theta_{i} & -\sin \theta_{i} & \cos \theta_{i} & \sin \theta_{i}
\end{array}\right]
$$

The second transformation relates the displacements $u$ and $v$ at both ends of the strut to the global displacements, $\mathrm{u}, \mathrm{v}$ and $\varphi$, at the internal nodes of the panel element. It must be noted that each strut has one end connected to a dummy node and the other end connected directly to an internal node (see Fig. 7). Therefore the second transformation needs to be formulated in two steps. The first step considers the relationship between the displacements at the internal dummy node $\mathrm{j}$ and the adjacent internal nodes $\mathrm{m}$ and $\mathrm{n}$ :

$$
\left\{\begin{array}{l}
u_{j} \\
v_{j}
\end{array}\right\}_{D}=[Q]_{I D}\left\{\begin{array}{l}
u_{m} \\
v_{m} \\
\varphi_{m} \\
u_{n} \\
v_{n} \\
\varphi_{n}
\end{array}\right\}
$$

where the sub-indexes D and I refers to dummy and internal nodes, respectively. The matrix $[\mathrm{Q}]_{\mathrm{ID}}(2 \mathrm{x} 6)$ can be formulated using interpolation functions which relates the displacements $\mathrm{u}$ and $\mathrm{v}$ corresponding to a point located at a distance $\mathrm{s}$ from the internal node. It is found (Crisafulli, 1997) that the terms of this matrix are:

$$
\begin{aligned}
& Q(1,1)_{I D}=Q_{1} \cos ^{2} \theta_{E}+Q_{5} \operatorname{sen}^{2} \theta_{E} \\
& Q(1,2)_{I D}=Q(2,1)_{I D}=\left(Q_{1}-Q_{5}\right) \cos \theta_{E} \operatorname{sen} \theta_{E} \\
& Q(1,3)_{I D}=Q_{2} \cos \theta_{E} \\
& Q(1,4)_{I D}=Q_{3} \cos ^{2} \theta_{E}+Q_{6} \operatorname{sen}^{2} \theta_{E} \\
& Q(1,5)_{I D}=Q(2,4)_{I D}=\left(Q_{3}-Q_{6}\right) \cos \theta_{E} \operatorname{sen} \theta_{E} \\
& Q(1,6)_{I D}=Q_{4} \cos \theta_{E} \\
& Q(2,2)_{I D}=Q_{1} \sin ^{2} \theta_{E}+Q_{5} \cos ^{2} \theta_{E} \\
& Q(2,3)_{I D}=Q_{2} \sin \theta_{E} \\
& Q(2,5)_{I D}=Q_{3} \sin ^{2} \theta_{E}+Q_{6} \cos ^{2} \theta_{E} \\
& Q(2,6)_{I D}=Q_{4} \sin \theta_{E}
\end{aligned}
$$


where $\theta_{\mathrm{E}}$ is the inclination of the edge (see Fig. 7),

$$
\begin{aligned}
& Q_{1}=1-3 \chi^{2}+2 \chi^{3} \\
& Q_{2}=\left(\chi-2 \chi^{2}+\chi^{3}\right) L_{E} \\
& Q_{3}=3 \chi^{2}-2 \chi^{3} \\
& Q_{4}=\left(-\chi^{2}+\chi^{3}\right) L_{E} \\
& Q_{5}=1-\chi \\
& Q_{5}=\chi
\end{aligned}
$$

$\mathrm{L}_{\mathrm{E}}$ is the length of the edge and $\chi=\mathrm{s} / \mathrm{L}_{\mathrm{E}}$.

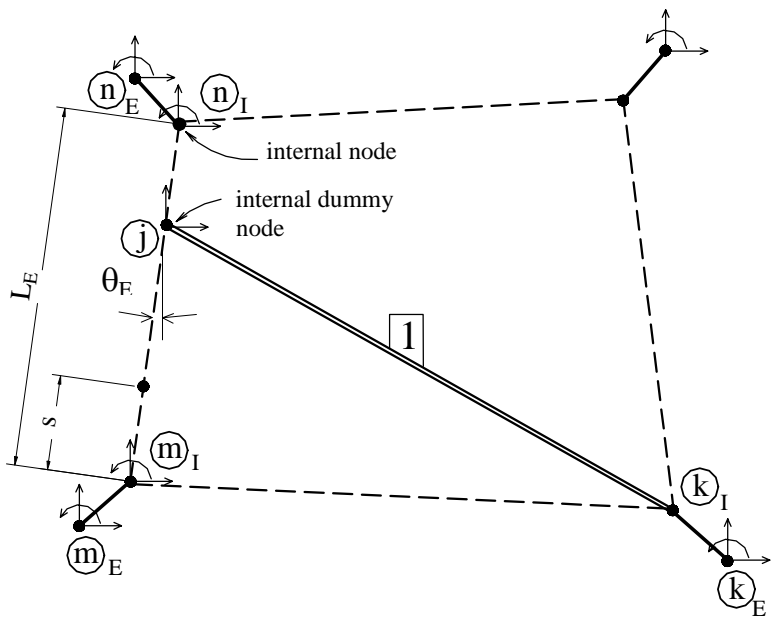

Figure 7. Detail of one edge of the panel element.

At the other end (node k) the strut is directly connected to an internal node and no special calculations are required for the second step in this transformation. Based on this consideration, and taking into account Eq. (8), the relationship between the displacement at $\mathrm{u}$ and $\mathrm{v}$ at the end of the strut and the global displacements at the three internal nodes (represented by subindex I) related to the strut is:

$$
\left\{\begin{array}{l}
u_{j} \\
v_{j} \\
u_{k} \\
v_{k}
\end{array}\right\}=[Q]_{B}\left\{\begin{array}{l}
u_{m} \\
v_{m} \\
\varphi_{m} \\
u_{n} \\
v_{n} \\
\varphi_{n} \\
u_{k} \\
v_{k} \\
\varphi_{k}
\end{array}\right\}
$$

where the matrix $[\mathrm{Q}]_{\mathrm{B}}$ includes the transformation defined by Eq. (11):

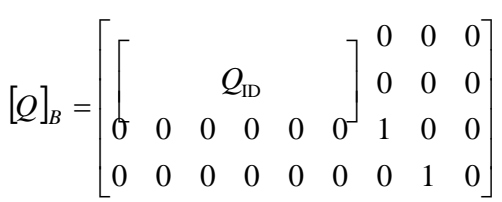

The final transformation relates the displacements of the internal nodes to the displacement of the external nodes. This relationship for one node is given by:

$$
\left\{\begin{array}{l}
u \\
v \\
\varphi
\end{array}\right\}_{I}=[Q]_{E I} \quad\left\{\begin{array}{l}
u \\
v \\
\varphi
\end{array}\right\}_{\mathrm{E}}
$$

where the matrix $[\mathrm{Q}]_{\mathrm{EI}}$ is a function of the horizontal and vertical offsets, $x_{o m}$ and $y_{o m}$, corresponding to node $m$, see Fig. 6 (b):

$$
[Q]_{E I}=\left[\begin{array}{ccc}
1 & 0 & -y_{\text {om }} \\
0 & 1 & x_{\text {om }} \\
0 & 0 & 1
\end{array}\right]
$$

The transformation indicated by Eq. (14) needs to be applied three times, since each strut is related to three external nodes. For example, the strut 1 in Fig. 6(a) contributes to the external nodes 1,2 and 4 . Therefore, the complete transformation is:

$$
\left\{\begin{array}{l}
u_{m} \\
v_{m} \\
\varphi_{m} \\
u_{n} \\
v_{n} \\
\varphi_{n} \\
u_{k} \\
v_{k} \\
\varphi_{k}
\end{array}\right\}_{E}\left\{[]_{C}\left\{\begin{array}{l}
u_{m} \\
v_{m} \\
\varphi_{m} \\
u_{n} \\
v_{n} \\
\varphi_{n} \\
u_{k} \\
v_{k} \\
\varphi_{k}
\end{array}\right\}\right.
$$

where the transformation matrix is:

$$
[Q]_{C}=\left[\begin{array}{ccccccccc}
1 & 0 & -y_{\text {om }} & 0 & 0 & 0 & 0 & 0 & 0 \\
0 & 1 & x_{\text {om }} & 0 & 0 & 0 & 0 & 0 & 0 \\
0 & 0 & 1 & 0 & 0 & 0 & 0 & 0 & 0 \\
0 & 0 & 0 & 1 & 0 & -y_{\text {on }} & 0 & 0 & 0 \\
0 & 0 & 0 & 0 & 1 & x_{\text {on }} & 0 & 0 & 0 \\
0 & 0 & 0 & 0 & 0 & 1 & 0 & 0 & 0 \\
0 & 0 & 0 & 0 & 0 & 0 & 1 & 0 & -y_{o k} \\
0 & 0 & 0 & 0 & 0 & 0 & 0 & 1 & x_{o k} \\
0 & 0 & 0 & 0 & 0 & 0 & 0 & 0 & 1
\end{array}\right]
$$

The complete procedure for the formulation of the stiffness matrix can be summarized in the following steps:

a) Select the active struts in the model (1 and 3, or 2 and 4) depending on the direction of the loading.

b) Evaluate the axial stiffness of the strut $\mathrm{i}, \mathrm{k}_{\mathrm{a}}$, using Eq. (2).

c) Calculate the stiffness matrix referred to the global displacements $\mathrm{u}$ and $\mathrm{v}$ at both ends of the strut, according to Eqs. (5b) and (7):

$$
\begin{aligned}
& {\left[K_{i}\right]_{\mathrm{A}}=[Q]_{A}^{T}} \\
& \left(\begin{array}{l}
4 \times 4) \\
(4 \times 1)
\end{array}\right.
\end{aligned}
$$

d) Calculate the stiffness matrix of the strut referred to the three internal nodes (with three degrees of freedom at each 
node, $\mathrm{u}, \mathrm{v}$ and $\varphi$ ), considering Eqs. (5b) and (12)

$$
\begin{aligned}
& {\left[K_{i}\right]_{\mathrm{B}}=[Q]_{B}^{T} \quad\left[K_{i}\right]_{\mathrm{A}} \quad[Q]_{B}} \\
& (9 \times 9) \quad(9 \times 4) \quad(4 \times 4) \quad(4 \times 9)
\end{aligned}
$$

e) Calculate the stiffness matrix of the strut referred to the three external nodes (with three degrees of freedom at each node, $\mathrm{u}, \mathrm{v}$ and $\varphi$ ), based on Eqs. (5b) and (16)

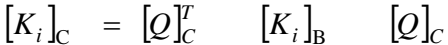

$$
\begin{aligned}
& (9 \times 9) \quad(9 \times 9) \quad(9 \times 9) \quad(9 \times 9)
\end{aligned}
$$

f) Assemble the terms of the matrix $\left[\mathrm{K}_{\mathrm{i}}\right]_{\mathrm{C}}$ into the matrix of the panel element, $\left[\mathrm{K}_{\mathrm{p}}\right],(12 \times 12)$, taking into account the nodes related to the strut. In the case of the strut 1 , which is related to the external nodes 1,2 and 4 , the contribution of this strut to the total stiffness matrix is:

$$
\left[K_{p}\right]=\left[\begin{array}{llllllllllll}
* & * & * & * & * & * & 0 & 0 & 0 & * & * & * \\
* & * & * & * & * & * & 0 & 0 & 0 & * & * & * \\
* & * & * & * & * & * & 0 & 0 & 0 & * & * & * \\
* & * & * & * & * & * & 0 & 0 & 0 & * & * & * \\
* & * & * & * & * & * & 0 & 0 & 0 & * & * & * \\
* & * & * & * & * & * & 0 & 0 & 0 & * & * & * \\
0 & 0 & 0 & 0 & 0 & 0 & 0 & 0 & 0 & 0 & 0 & 0 \\
0 & 0 & 0 & 0 & 0 & 0 & 0 & 0 & 0 & 0 & 0 & 0 \\
0 & 0 & 0 & 0 & 0 & 0 & 0 & 0 & 0 & 0 & 0 & 0 \\
* & * & * & * & * & * & 0 & 0 & 0 & * & * & * \\
* & * & * & * & * & * & 0 & 0 & 0 & * & * & * \\
* & * & * & * & * & * & 0 & 0 & 0 & * & * & *
\end{array}\right]
$$

where the symbol * indicates a nonzero term in the matrix, which is obtained from matrix $\left[\mathrm{K}_{\mathrm{i}}\right]_{\mathrm{C}}$.

g) Repeat the same process for the second strut in the model in order to complete the stiffness matrix of the panel element.

A similar process of successive transformations should be applied in order to assemble the vector of nodal forces (12 terms), based on Eq. (5a).

\subsection{Shear behaviour of the spring}

The consideration of the shear behaviour of the panel element is simpler, since only one spring element is used. This spring is connected to two diagonally opposite internal nodes depending on the direction of the shear force, see Fig. 6(b). It is worth noting that the implementation of the proposed model in a panel element allows the calculation of the axial forces in the struts to be used for evaluating the strength of the shear spring. This inter-relationship between different members is not possible to be considered in most of the existing programs for structural analysis.

The stiffness of the spring and the shear force are associated with the horizontal displacement, u, of the two diagonally opposite nodes (nodes 1and 3 or 2 and 4 , depending on the loading direction). Consequently, the stiffness matrix of the shear spring related to the displacements of the internal nodes $n$ and $\mathrm{k}$ is:

$$
\left[K_{s}\right]=\left[\begin{array}{cccccc}
k_{s} & 0 & 0 & -k_{s} & 0 & 0 \\
0 & 0 & 0 & 0 & 0 & 0 \\
0 & 0 & 0 & 0 & 0 & 0 \\
-k_{s} & 0 & 0 & k_{s} & 0 & 0 \\
0 & 0 & 0 & 0 & 0 & 0 \\
0 & 0 & 0 & 0 & 0 & 0
\end{array}\right]
$$

where the term $k_{s}$ is defined by Eq. (1). The only transformation required in this case is that given by Eqs. (13) and (14), which relate the internal nodes to the external nodes:

$$
\left\{\begin{array}{l}
u_{n} \\
v_{n} \\
\varphi_{n} \\
u_{k} \\
v_{k} \\
\varphi_{k}
\end{array}\right\}_{E}=[Q]_{D}\left\{\begin{array}{l}
u_{n} \\
v_{n} \\
\varphi_{n} \\
u_{k} \\
v_{k} \\
\varphi_{k}
\end{array}\right\}
$$

where the transformation matrix is:

$$
[Q]_{D}=\left[\begin{array}{cccccc}
1 & 0 & -y_{o n} & 0 & 0 & 0 \\
0 & 1 & x_{o n} & 0 & 0 & 0 \\
0 & 0 & 1 & 0 & 0 & 0 \\
0 & 0 & 0 & 1 & 0 & -y_{o k} \\
0 & 0 & 0 & 0 & 1 & x_{o k} \\
0 & 0 & 0 & 0 & 0 & 1
\end{array}\right]
$$

Based on Eq. (5b), the stiffness matrix of the shear spring related to the external to two external nodes of the panel is:

$$
\begin{array}{llll}
{\left[K_{s}\right]_{\mathrm{D}}=} & {[Q]_{D}^{T}} & {\left[K_{s}\right]} & {[Q]_{D}} \\
(6 \times 6) & (6 \times 6) & (6 \times 6) & (6 \times 6)
\end{array}
$$

Finally, the terms of the matrix $\left[\mathrm{K}_{\mathrm{s}}\right]_{\mathrm{D}}$ need to be added to the total stiffness matrix $\left[\mathrm{K}_{\mathrm{p}}\right]$ considering that the shear spring is connected to nodes 1 and 3 or 2 and 4 , depending on the loading direction.

\section{CONSIDERATIONS FOR 3-D MODELS}

In recent years there has been a significant increase in both the power of computers and the capacity of the software available for structural analysis. As a result, today it is possible to perform the nonlinear analysis of complete structures using 3D models.

The strut model (single or multi-strut) has been developed and used to evaluate the in-plane behaviour of masonry infills, however, the out-of-plane response cannot be adequately represented because the infill behaves as an unreinforced slab. When implementing the proposed model in a 3-D computer program the following considerations should be taken into account. The masonry panel in the model should be a plane panel (in the undeformed state). This means than the four nodes of the panel should be in a plane. If the panel is not plane, other effects can be important (shell or membrane behavior), which are not considered in the model presented here. When the 
direction normal to the panel coincides with one of the global axes (e.g. the axis Z), the solution is simple. It must be considered that the stiffness matrix of the panel $(12 \times 12)$ contributes only to the 12 global degrees of freedom in the plane of the panel (XY). In this case, the displacements along $\mathrm{Z}$ and the rotations about $\mathrm{X}$ and $\mathrm{Y}$ should be ignored, because the model is not able to represent the out-of-plane behaviour.

A more precise representation of the spatial behaviour of the infill frame will require the consideration of the out of plane response. For example, the panel can be considered as a "slab", but this behaviour probably degrades rapidly as the displacement increases. This complex representation of the infill panel exceeds the scope of the strut model, which is applied as a simplified representation. For more refined modeling, the use of 2-D or 3-D nonlinear finite elements to represent the entire panel could be a proper solution.

\section{NUMERICAL EXAMPLES}

The proposed model was applied to represent the response of a infilled frame tested at the University of Canterbury under vertical and cyclic lateral loading, in which a shear failure occurred (Crisafulli, 1997). Using the computer program RUAUMOKO (Carr, 2000), the lateral and vertical forces were applied in successive increments, in which the mechanical properties of the structure were updated according to the strains and displacements induced in the different components of the model in the previous step. The separation of the struts was adopted as $h_{z}=0.23 \mathrm{~m}$, which is equivalent to $\mathrm{z} / 2$. The properties of the model associated with the axial cyclic behaviour of masonry were adopted from tests of the materials.

Figure 8 compares experimental and analytical results in the range of small displacements in order to observe clearly the response in the initial stage. The force level at which shear cracking occurs according to the analytical procedure, $59.8 \mathrm{kN}$, agrees very well with the measured value equal to $65.0 \mathrm{kN}$. The overall theoretical response is compared in Fig. 9 with the strength envelope measured during the test, indicating that the proposed model can estimate the lateral resistance of the infilled frame and the strength degradation observed for large displacements. In addition, the failure mechanism is properly represented, being the analytical model capable of describing the shear cracking of the masonry panel and the yielding of the tension column of the frame.

The proposed model has been also implemented in the program SesimiStruct (SesimiSoft, 2006) and numerical results were compared to experimental data by Smyrou et al. (2006), showing the accuracy of the model to evaluate the nonlinear response of the structure. Furthermore, they conducted an interesting sensitivity analysis to evaluate the relative importance of the parameters used in the model to represent the cyclic response of masonry.

\section{CONCLUSIONS}

This paper describes a refined macroscopic model for infilled frames, in which the principal premises are the rational consideration of the particular characteristics of masonry and the adequate representation of the hysteretic response.
Since shear failure of the masonry (shear friction and diagonal tension failure) is the most common type of failure observed in a masonry panel, a multi-spring model is developed to represent specifically this situation. The model accounts separately for the compressive and shear behaviour of masonry using a double truss mechanism and a shear spring in each direction. The proposed configuration allows the calculation of the axial forces in the strut to be used for the evaluation of the shear strength of the masonry panel. This concept is implemented in a 4-node panel element which is being incorporated in the computer program RUAUMOKO (Carr, 2000).

The comparisons between experimental data obtained by the authors and other researchers and analytical results indicate that the cyclic response of infilled frames can be properly represented by the proposed model. This, however, requires a fine calibration of the model, which is usually achieved after several adjustments, particularly the parameter defining the hysteretic behaviour of masonry. The need of these adjustments indicates that the detail prediction of the real cyclic response of infilled frames is still a difficult task.

Recommendations are also given for the analysis of infilled frames when failure due to crushing of the corners is expected in the masonry panels. Further research is required in order to implement this model.

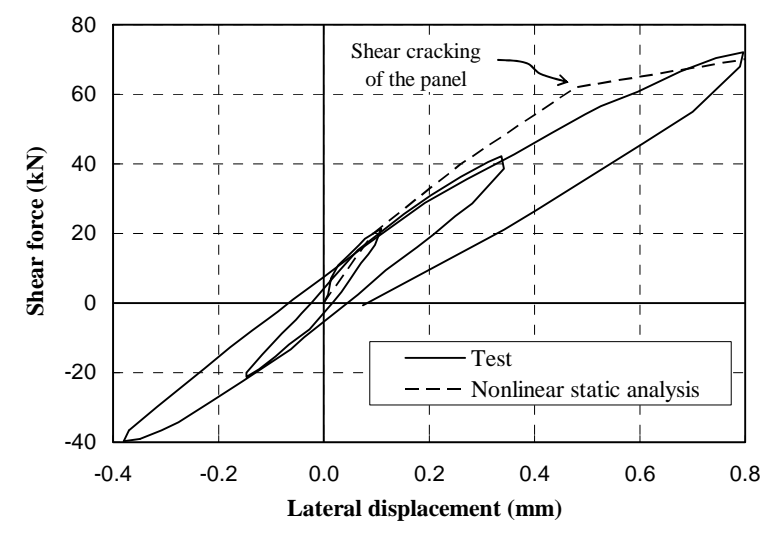

Figure 8. Comparison between experimental and analytical data in the range of small displacements.

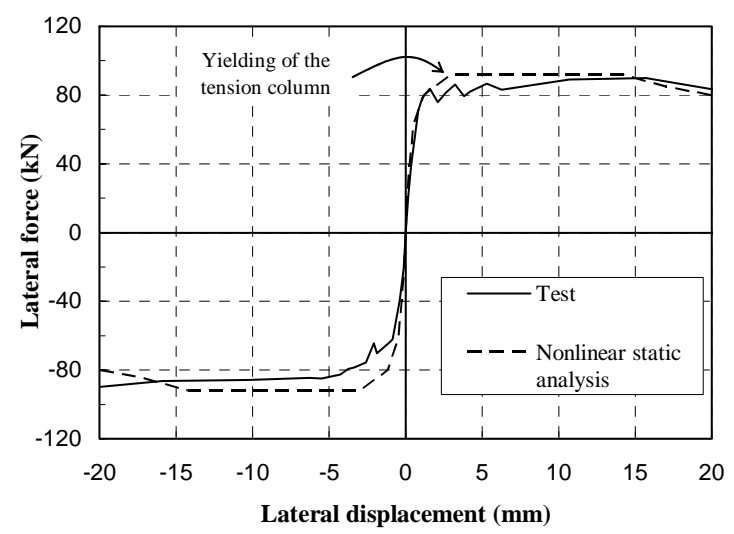

Figure 9. Comparison between experimental and analytical data in the range of small displacements. 


\section{ACKNOWLEDGMENTS}

The authors express their deepest gratitude to the late Professor Robert Park for his invaluable guidance and continuous support over the duration of this project. Thanks are also given to Dr. José I. Restrepo for his useful advice and interest in this research programme.

This investigation was conducted as part of the $\mathrm{PhD}$ thesis of the first author. The scholarship provided by the Ministry of External Relations and Trade of New Zealand and the financial assistance given by the Facultad de Ingeniería, Universidad Nacional de Cuyo, Argentina, are gratefully acknowledged.

\section{REFERENCES}

ABAQUS: Theory Manual and User's Manual, Hibbitt, Karlsson \& Sorensen Inc.

Carr, A. J. (2002) RUAUMOKO: Inelastic Dynamic Analysis, Department of Civil Engineering, University of Canterbury.

Crisafulli, F. J. (1997). Seismic Behaviour of Reinforced Concrete Structures with Masonry Infills, PhD Thesis, Department of Civil Engineering, University of Canterbury, $404 \mathrm{p}$.

Crisafulli, F. J., Carr, A. J. and Park, R. (2000). “Analytical Modelling of Infilled Frame Structures - A General Review”. Bulletin of the New Zealand Society for Earthquake Engineering, Vol. 33, No. 1, pp 30-47.

Crisafulli, F., Carr, A. and Park, R.(2002). "Rational Evaluation of the Lateral Strength of Infilled Frames", 7th National Conference on Earthquake Engineering, Boston, USA.

Decanini, L. D. and Fantin, G. E. (1986). "Modelos simplificados de la mampostería incluida en pórticos. Características de rigidez y resistencia lateral en estado límite” (in Spanish), Jornadas Argentinas de Ingeniería Estructural, Buenos Aires, Argentina, Vol. 2, pp. 817-836.

Holmes, M. (1961). "Steel Frames with Brickwork and Concrete Infilling”, Proceedings of the Institution of Civil Engineers, Vol. 19, pp. 473-478.

Livesly, R. K. (1975) Matrix Methods of Structural Analysis, Second Edition, Pergamon Press, 277 p.

Mallick, D. V. and Severn, R. T. (1967) "The Behaviour of Infilled Frames under Static Loading", Proceedings of the Institution of Civil Engineering, Vol. 38, pp. 639-656.

Mann, W. and Müller, H. (1982). "Failure of Shear-Stressed Masonry - An Enlarged Theory, Tests and Application to Shear Walls”, Proceedings of the British Ceramic Society, Vol. 30, pp. 223-235.

Stafford Smith, B. (1962). "Lateral Stiffness of Infilled Frames", Proceedings of the American Society of Civil Engineering, Journal of Structural Division, Vol. 88, No. ST6, pp. 183-199.
Stafford Smith, B. (1966). "Behaviour of Square Infilled Frames”, Proceedings of the American Society of Civil Engineering, Journal of Structural Division, Vol. 92, No. ST1, pp. 381-403.

SeismoSoft (2006), SesimoStruct - A Computer Program for the Static and Dynamic Analysis of Framed Structures, http://www.seismosoft.com.

Smyrou, E., Blandon-Uribe, C., Antoniou, S., Pinho, R. and Crowley, H. (2006). " Implementation and Verification of a Masonry Panel Model for Nonlinear Pseudo-Dynamic Analysis of Infilled RC Frames”, Proceedings of the First European Conference on Earthquake Engineering and Seismology. Geneva, Switzerland. 